\section{Depth}

While it is obvious that every interested student will endeavour to increase their depth of knowledge, I think this has particular relevance to MCQ study. A guiding principle is that it is more difficult to judge an unrecognisable statement as false, than to assert a recognisable one as true. In my opinion, this is the most fundamental truth underlying the composition of MCQ tests. The reason for this lies in the limited or finite quanta of knowledge known about any topic, as compared to the infinite number of false statements that may be proposed. Thus, there are only so many documented side effects of tricyclic drugs, or clinical features of Klinefelter's syndrome, but limitless opportunity to pose untrue or non-documented side effects or clinical features respectively. When faced with a statement or association which the student has not seen or considered before, the more depth of knowledge he can recruit in that area, the more confident can he be in asserting the falsehood of untrue propositions. Increased depth of familiarity should reduce the recurrent dilemma in the exam when faced with a novel association of "Well, I have not seen this before but it looks quite possible!" As the depth of the exam is often set at the level of reference papers to major topics, reading the reference articles from one's major textbook is the most direct route to harmonising one's study and the exam itself.

\section{Conclusion}

MCQ tests focus on the evaluation of propositional statements. Ongoing evaluation of knowledge in MCQ terms as a formal discipline can be both a stimulating adjunct to general study and can improve exam performance.

\title{
The psychiatric MCQ: are 'possibles' always true?
}

\author{
Jonathan I. Bisson, Registrar, Queen Elizabeth Military Hospital, London SE18 4JR
}

\author{
"Depression of mood may be caused by \\ Propranolol \\ Reserpine \\ Clonidine \\ Frusemide \\ Digoxin"
}

The above specimen MRCPsych Part 1 question (Royal College of Psychiatrists, 1989) illustrates well the difficulties facing the examination candidate who is required to make a TRUE/FALSE/DON'T KNOW decision in the knowledge that an incorrect response will result in a negative mark.

The term "may be" in this question is problematic. Holden's (1987) useful book on examination techniques states " 'may be' means that it is recognised (i.e. reported) to occur." "May be" appears to imply a possibility, however remote. Therefore the prudent candidate is likely to answer TRUE to the vast majority of such questions assuming that most things are possible. But frusemide and digoxin? Surely not?

The sources of information open to the average candidate produce a variety of answers to the original question.

The Oxford Textbook of Psychiatry (Gelder et al, 1988) states that diuretics may cause depression due to electrolyte depletion, that digitalis may cause mood disturbance and that both reserpine and sympathetic blockers may cause depression. No mention is made of clonidine. This information allows us to answer the question TT?TT.

The Association of the British Pharmaceutical Industry Data Sheet Compendium 1989-90 states that depression is a possible side effect with clonidine and a possible toxic effect of digoxin. Depression is not among the possible side effects listed of propranolol and frusimide. Reserpine has no entry. Our answer from this source is ??T? or F?TFT if we assume the adverse effects listed to be exhaustive.

The British National Formulary (1990) provides a ?TT?? answer or FTTFF answer. Also stated is the fact that "any drug MAY produce unwanted or unexpected adverse reactions" suggesting a TTTTT response is perhaps correct.

Other sources of information, including journals, throw further light on to the question. Reserpine, which acts as an antihypertensive by depleting tissue stores of monoamines, has long been suspected of causing depression by the same mechanism. Similarly, clonidine decreases monoamine availability at the synapse, exerting its effect through pre-synaptic alpha 2 adrenoceptor agonism. It may cause depression through the same mechanism.

Propranolol and other beta blockers have been associated with depression in several studies. For example, Avorn et al (1986) showed that $23 \%$ of a large population taking beta blockers for two years were prescribed a tricyclic antidepressant in that 
time; a significantly higher proportion than of those taking other drugs including the much maligned reserpine. The exact mechanism is unknown, although various suggestions have been made (Koella, 1985). This does not PROVE propranolol causes depression, but suggests it may do so.

Digoxin as a cause of depression is less widely quoted. However, Schouten \& Van der Aa (1984) described an 85-year-old female who was suffering from depression "caused" by digoxin intoxication. This particular literature search provided no papers on frusemide as a cause of depression. Overall the assumption that most things are possible is reinforced.

What of reports received by the Committee on Safety of Medicines? Depression has been reported as an adverse effect of all of them except digoxin (Committee on Safety of Medicines, personal communication). A TTTT? or TTTTF response.

Using all the sources listed above, all five drugs in the question have been implicated somewhere as a cause of depression of mood. Hence an answer of TTTTT would appear to be required for maximum marks. But is this an adequate or indeed fair way of assessing knowledge of psychiatry and related topics, which, after all, should be the main aim of the MRCPsych Part 1 MCQ paper?

In order to say something is a possibility is relatively easy; one report is all that is required. On the other hand, in order to say something "does not" occur requires a different level of.knowledge. It requires the knowledge that it has never been reported, which ultimately requires knowledge of everything ever published on the subject in question. Such a vast amount of knowledge is required to know for certain that something does not occur, that it is virtually beyond the reach of any one individual.

In conclusion, MCQs of this nature are a poor method of assessing knowledge and any questions concerned with possibilities should be omitted from future papers. At present it would appear that answering TRUE every time the word "may" arises should gain maximum marks.

\section{References}

Association of the British Pharmaceutical Industry Data SheEt Compendium (1989-1990) London: Datapharm Publications.

Avorn, J., EveritT, D. E. \& Weiss, S. (1985) Increased antidepressant use in patients prescribed beta-blockers. Journal of the American Medical Association, 255, 257-260.

British National Formulary Number 19 (1990) London: British Medical Association and The Pharmaceutical Society of Great Britain.

GelDER, M., GATH, D. \& MAYOU, R. (1988) Oxford Textbook of Psychiatry. Oxford: Oxford University Press.

HOLDEN, N. L. (1987) Examination Techniques in Psychiatry, p. 12. London: Hodder \& Stoughton.

Koella, W. P. (1985) CNS-related (side-) effects of betablockers with special reference to mechanisms of action. European Journal of Clinical Pharmacology, 28 supplement, 55-63.

Royal College of Psychiatrists (1989) Sample set of MRCPsych examination papers. London: Royal College of Psychiatrists.

SCHOUTEN, J. \& VAN DER AA, G. G. (1984) A patient with depression due to digitalis poisoning. Tijdschrift Voor Gerontologie en Geriatrie, 15, 63-65.

See Correspondence, p 108 